\title{
"Man stelle sich einen Hügel vor". La descripción fotográfica en Winter in Vorderasien de Annemarie Schwarzenbach
}

\author{
Guiomar Susana Topf Monge \\ Universidad Pablo de Olavide \\ gstopmon@upo.es
}

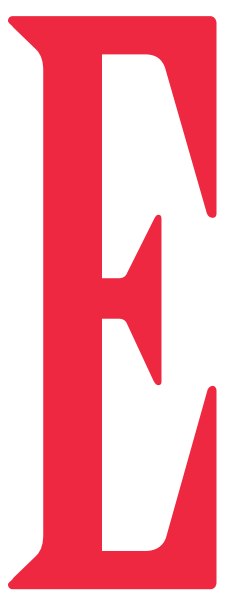

n 1933 la escritora suiza Annemarie Schwarzenbach viaja a Oriente como reportera del semanario Zürcher Illustrierte. Durante siete meses acompaña a un grupo de arqueólogos afincados en Estambul, y con ellos visita Oriente Próximo. Viaja en el Taurus Express a las ciudades de Ankara, Kayseri y Konya. Se adentra en Siria y, desde allí, viaja a Líbano y Palestina para llegar a través de Iraq a Persia, como entonces todavía se llamaba Irán. El relato de esta experiencia queda plasmado en artículos y fotos y, finalmente, en una novela que Schwarzenbach publicará en 1934: Winter in Vorderasien. Tagebuch einer Reise.

La editorial Rascher anunciaba este libro como "modernes Reisebuch" y en el Klappentext ponía que se trataba del diario que una "Künstlerin" escribió durante un exótico viaje por Asia Menor. En los años 20 y 30 estaban de moda este tipo de relatos "auténticos", tanto en forma de libros como de publicaciones periodísticas. De hecho, Winter in Vorderasien incluye fotografías que la propia autora tomó durante el viaje y que dan fe de las experiencias relatadas en el diario de viaje. El texto resulta realmente cautivador, hasta el día de hoy, por los parajes tan recónditos que describe de primera mano y por la sensibilidad con que lo hace.

\section{Un viaje por Oriente Próximo: la descripción fotográfica}

El viaje de Schwarzenbach comienza, pues, en Estambul. Es el 15 de octubre de 1933 y los viajeros europeos entran en contacto con el mundo oriental y musulmán de bazares y mezquitas. En su diario describe los colores de tejidos y alfombras, los olores de los alimentos y el ruido de niños, comerciantes y artesanos en los estrechos callejones.

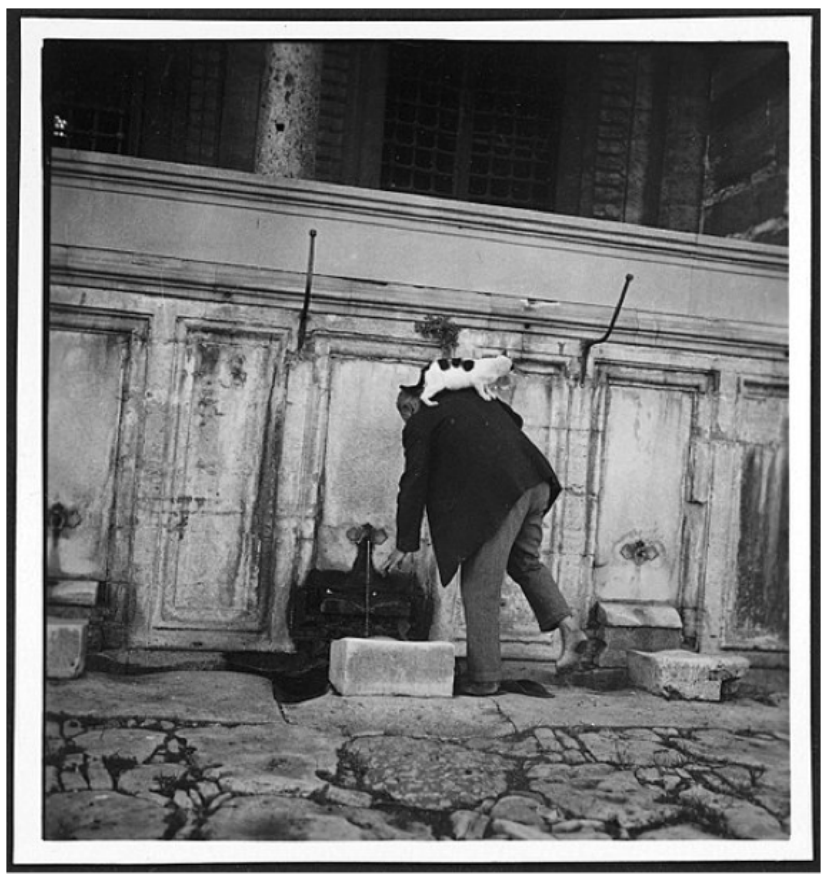




\section{Resumen:}

Winter in Vorderasien. Tagebuch einer Reise (1934) de la escritora y fotógrafa suiza Annemarie Schwarzenbach presenta diversos vínculos entre texto y fotografía: las fotografías que ilustran libro, las reflexiones sobre fotografía en el propio texto y las descripciones verbales que reproducen la técnica fotográfica. Este artículo estudia estos vínculos desde el debate sobre el 'Orientalismo' y revela que algunas descripciones fotográficas son écfrasis de fotografías existentes en el legado fotográfico de Schwarzenbach. Concluye que la técnica de la descripción fotográfica cumple la misma función que el estilo impersonal del relato: aumentar la objetividad y evitar las imágenes orientalizantes.

Palabras clave: Annemarie Schwarzenbach, literatura de viaje, Orientalismo, fotografía, descripción objetiva

\section{Zusammenfassung:}

In Winter in Vorderasien. Tagebuch einer Reise (1934) der Schweizer Schriftstellerin und Fotografin Annemarie Schwarzenbach werden verschiedene Schnittstellen zwischen Text und Fotografie aufgezeigt: Die das Buch illustrierenden Fotografien, die im Text befindlichen Reflexionen über das Fotografieren an sich und die beschreibenden Passagen, welche fotografische Techniken umsetzen. Dieser Aufsatz analysiert diese Schnittstellen aus der Perspektive der ,Orientalismus'-Debatte und belegt, dass die fotografischen Beschreibungen teilweise Ekphrasen der im Nachlass von Schwarzenbach real existierenden Fotografien sind. Der Beitrag kommt zu dem Schluss, dass die fotografische Technik in beschreibenden Textstellen dieselbe Funktion hat wie der unpersönliche Stil der Erzählung: die Objektivität zu erhöhen und orientalisierende Bilder zu umgehen.

Schlüsselwörter: Annemarie Schwarzenbach, Reiseliteratur, Orientalismus, Fotografie, objektive Beschreibung
Pero la reportera no ve sólo aquello que cualquier viajero buscaría en Estambul. Con ojo de fotógrafa se fija en detalles que a priori no entran en el repertorio de estereotipos occidentales sobre Oriente. Ve, por ejemplo, a un hombre con un gato sentado en su hombro: "Ein Mann ging langsam über den Platz, eine Katze auf dem Nacken. Als er sich an einem der Brunnen die Füße wusch, miaute sie ängstlich, sprang herab und strich durch das niedere Gras davon." (9)

Es una descripción objetiva y la única palabra que transporta cierta emoción (“ängstlich”) se refiere al gato. La observadora se mantiene al margen, no sabemos qué impresión le causó la escena. Schwarzenbach no ofrece ninguna explicación para entender por qué el hombre lleva un gato al hombro.

En este sentido se puede hablar de "fotografisches Wahrnehmen" (De Bruyker 2011) o de descripción fotográfica: el texto reproduce la realidad de forma objetiva. La interpretación subjetiva viene dada por otros elementos, como la selección del motivo y lo que en una fotografía sería el encuadre. En este caso, Schwarzenbach escogió como motivo a un hombre turco con gato. El encuadre -la escena de lavarse los pies en una fuente pública- le pareció representativa de la vida en las calles de Estambul. Pero cualquier otro trazo de subjetividad queda anulado y la imagen surge como un testimonio objetivo y auténtico de cómo era Estambul en 1933.

Curiosamente, Schwarzenbach no sólo describió sino que también hizo exactamente esa foto del hombre con el gato. No está incluida entre las fotos reproducidas en el libro Winter in Vorderasien, sino que la he encontrado entre las más de 7.000 fotografías de Schwarzenbach que están disponibles en los archivos de la Biblioteca Nacional Suiza .

Lo más probable es que la fotografía precediera al texto y que al sentarse a escribir el diario recordara el momento vivido -como viajera observadora y como reportera fotógrafa- o que incluso tuviese la fotografía delante y la describiera en el momento de redactar el libro de viaje a partir de las notas tomadas y de las fotografías ya reveladas.

No se puede decir que Schwarzenbach no estuviese condicionada por las fotografías estereotípicas de Oriente, las Postkarten del imaginario colectivo europeo. Cuando llega desde Estambul a Ankara, ve por primera vez camellos. Y los describe de forma absolutamente predecible: "Sie standen in langer Kette auf einem Hügelrücken, dunkel und groß

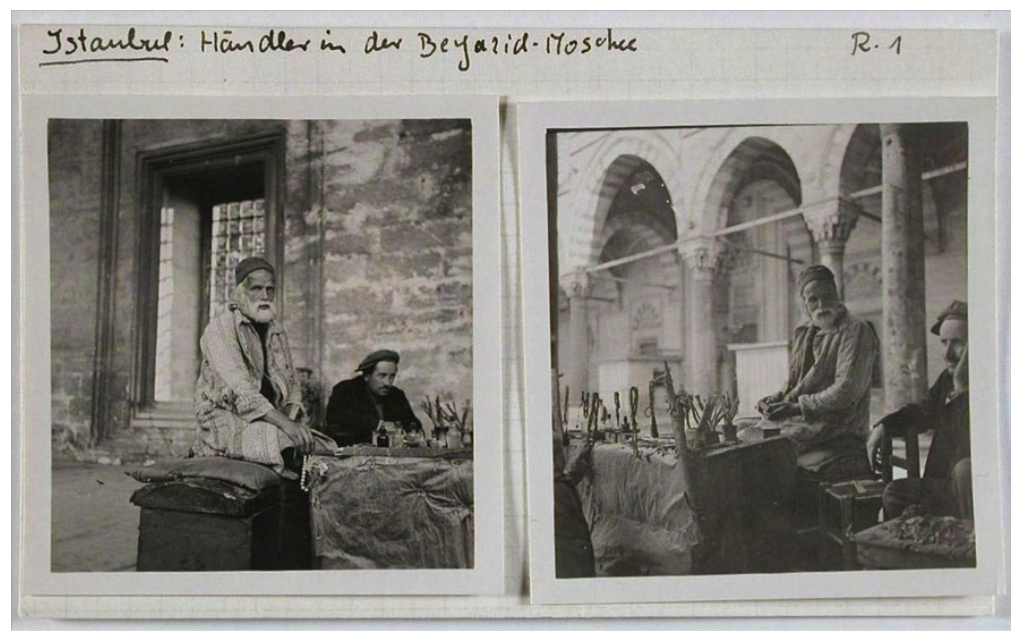




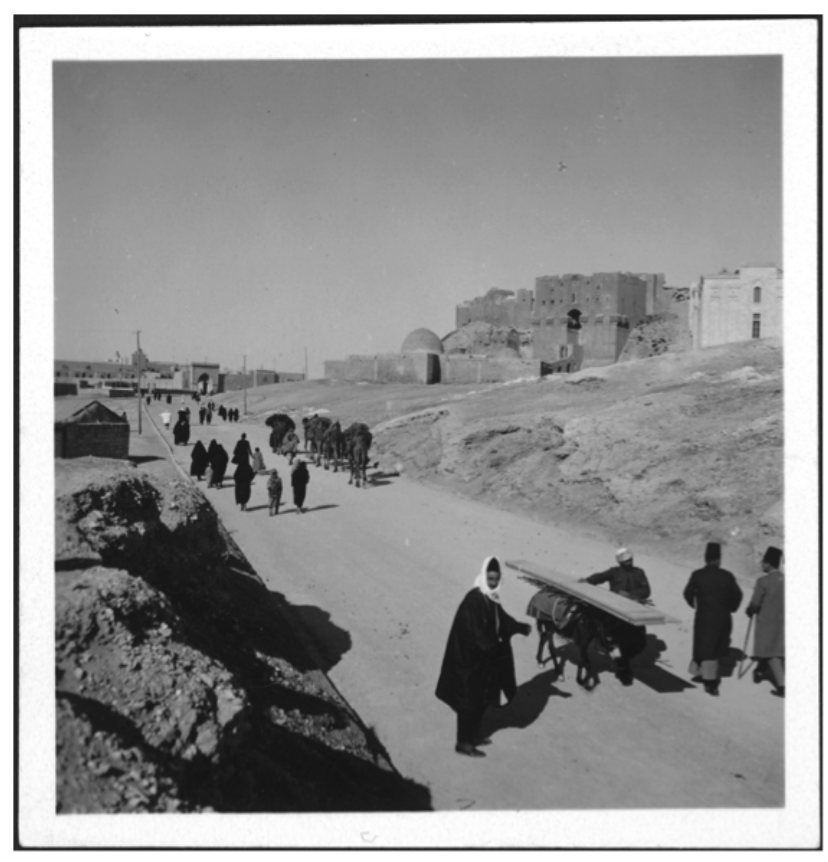

im leeren Himmel" (11). Una mirada desde el coche hacia el horizonte, donde los camellos aparecen de perfil, su silueta característica recortada contra el cielo al atardecer. El segundo encuentro con un camello, sin embargo, es del todo diferente: "Als ich mich einem Kamel bis auf zwei Meter genähert hatte, um es zu photographieren, wandte es mir sein uraltes Faltengesicht mit feuchtglänzenden Augen zu und folgte mir; ich fühlte seine wiegende Größe in meinem Rücken.” (12)

Aquí habla la fotógrafa y reportera profesional, que se acerca a un animal exótico y gigante hasta ver el brillo de sus ojos. Vemos que su ambición es captar todas las imágenes posibles de la forma más auténtica. Así lo corrobora la propia Schwarzenbach cuando comenta que quizás haya conseguido hacer una "gute Aufnahme" (7) de un comerciante turco sentado en el patio de la mezquita de Bayaceto. Y explica en qué consiste una buena fotografía: en captar los colores ("hellrot"), la textura ("zerschlissener Seidenmantel"), el gesto ("die Hand zum Handeln und Geldeinnehmen ausgestreckt wie zur würdigsten Verrichtung”) y la mirada del anciano: "einen Weisheitsblick auf uns richtend, voll schmerzerfahrener Gelassenheit und ganz ohne Hohn." (7)

Winter in Vorderasien es, pues, un diario en el que la autora también reflexiona sobre cómo fotografiar lo exótico de forma detallada y exacta. Stempel habla de que Schwarzenbach en este primer viaje fotografía a los "Einheimische" con una mezcla de exotismo y "Mitgefühl" (Stempel 2009: 100).

Creo que a esta interpretación hay que añadirle el esfuerzo por superar imágenes preconcebidas y por evitar distorsiones que puedan derivar de prejuicios occidentales.
En el caso del comerciante fotografiado en la mezquita de Bayaceto, por ejemplo, sería preconcebida la interpretación cristiana de que es indigno manejar dinero, en general, y con más razón en un recinto sagrado. Con su descripción de una fotografía en la que empatiza con el anciano y, por lo visto, sabio comerciante, Schwarzenbach se sobrepone a estos prejuicios.

La comprensión y aceptación de la cultura oriental no son meramente intuitivas. Según su más reciente biógrafo, Alexis Schwarzenbach (2008: 129), la autora se había preparado a conciencia antes de emprender el viaje. Había visitado museos y observado fotografías de viajes, ampliando considerablemente los conocimientos que, por su condición de historiadora, ya poseía sobre las regiones que visitaría.

Cuando visita lugares emblemáticos e históricos, los reconoce de haberlos visto en reproducciones fotográficas: "Es folgten alte kostbare Türen und Moschee- Eingänge, die ich auf Photographien gesehen hatte: von Sonne beleuchtet, mit schrägen, schwarzen Schatten." (38) La fotografía acompaña a Schwarzenbach desde antes de emprender el viaje, durante todo el periplo y hasta después de haber vuelto, a la hora de rememorar y contar lo que ha visto y lo que ha fotografiado.

Aunque la primera edición de Winter in Vorderasien, publicada en 1934, contenga 30 fotografías de este viaje, éstas no aportan información relevante. Únicamente ilustran, sintetizan y refuerzan lo que se describe en el texto (Stempel 2009: 157). Es probable que la selección y edición de las fotografías fuera llevada a cabo por los editores sin la colaboración de Schwarzenbach. Porque entre las fotos no publicadas de este viaje hay verdaderas obras de arte y que son relevantes desde el punto de vista antropológico y cultural, como la fotografía del hombre con el gato al hombro.

\section{Una escritora viajera: Ia narración impersonal}

Más que un diario, Winter in Vorderasien es un álbum de fotos verbalizado, una sucesión de imágenes que Schwarzenbach recopila durante el viaje. Para Schliecker (2008), esta novela está escrita como una especie de informe, como si la viajera levantara acta de un viaje. La tipología textual del informe como técnica literaria tiene dos funciones: por un lado muestra la realidad con la mayor objetividad posible, y por otro, reduce al narrador a una mera instancia, que opina e interviene lo menos posible.

Estas premisas del informe se cumplen hasta cierto punto: en ocasiones, el texto es tan objetivo e impersonal que el lector 
brechen; ihr Gekreisch wird vielfältig sein und das Echo der Felstäler wird es verhunderfältigen. (17)

En este sentido, el libro de viaje Winter in Vorderasien es ya un diario impersonal o un primer paso hacia ese diario impersonal. Y, en mi opinión, la técnica de la impersonalidad cumple la misma función que la fotografía y la descripción fotográfica analizada anteriormente.

Así como la descripción fotográfica se debate entre las representaciones preconcebidas y una percepción sin prejuicios, Schwarzenbach intentaría zafarse de los moldes culturales inherentes a la lengua alemana experimentando con un lenguaje imparcial y, por lo tanto, impersonal. La posición del yo narrador está extremadamente debilitada y difuminada, por las estructuras lingüísticas mencionadas, que hacen desaparecer al actante de la superficie textual. Con ello se pretende presentar la realidad oriental como algo que tiene su existencia independientemente de quien observa esa realidad.

La escritora viajera no puede desaparecer del todo, pues entonces tampoco sería verosímil lo que se anuncia desde el subtítulo: Tagebuch einer Reise promete un relato de primera mano. El texto presenta, por lo tanto, un yo narrador que,

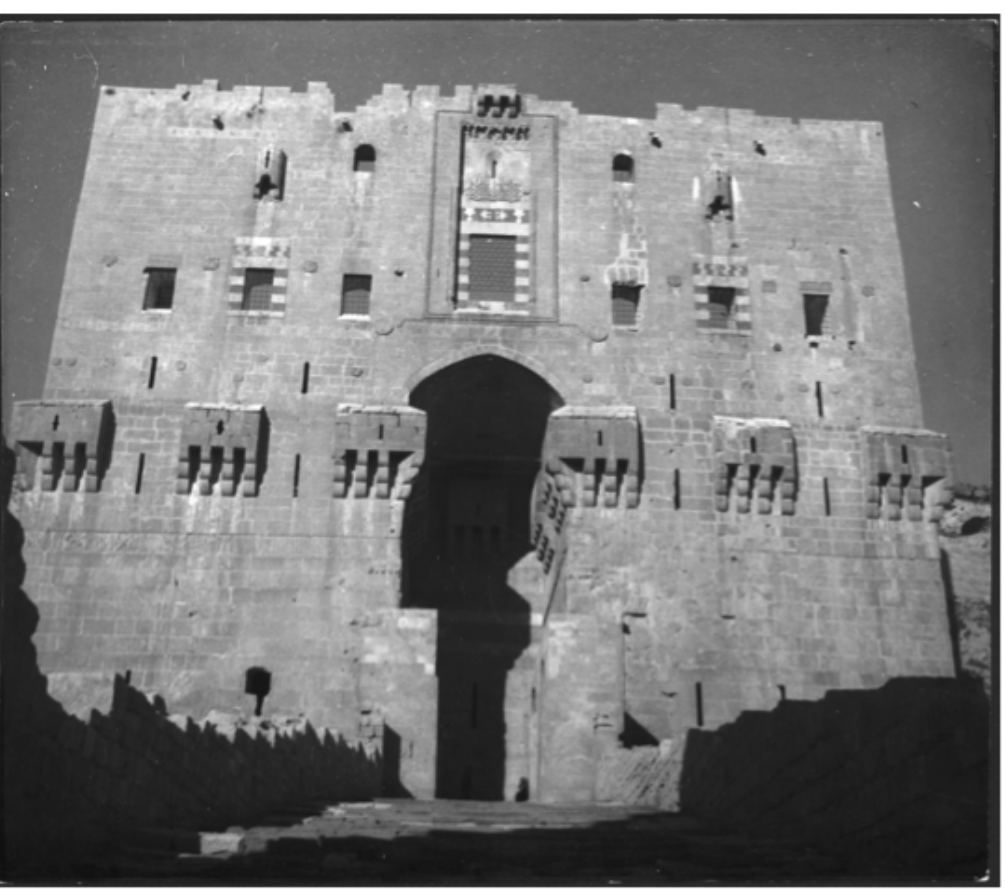

como hemos dicho, viaja acompañado por arqueólogos y diplomáticos, chóferes y guías. A ello también contribuye que se mantenga la forma de un diario, separando los capítulos por fechas ordenadas cronológicamente.

En Winter in Vorderasien se vislumbran rasgos de subjetividad cuando la autora reflexiona sobre los el valor

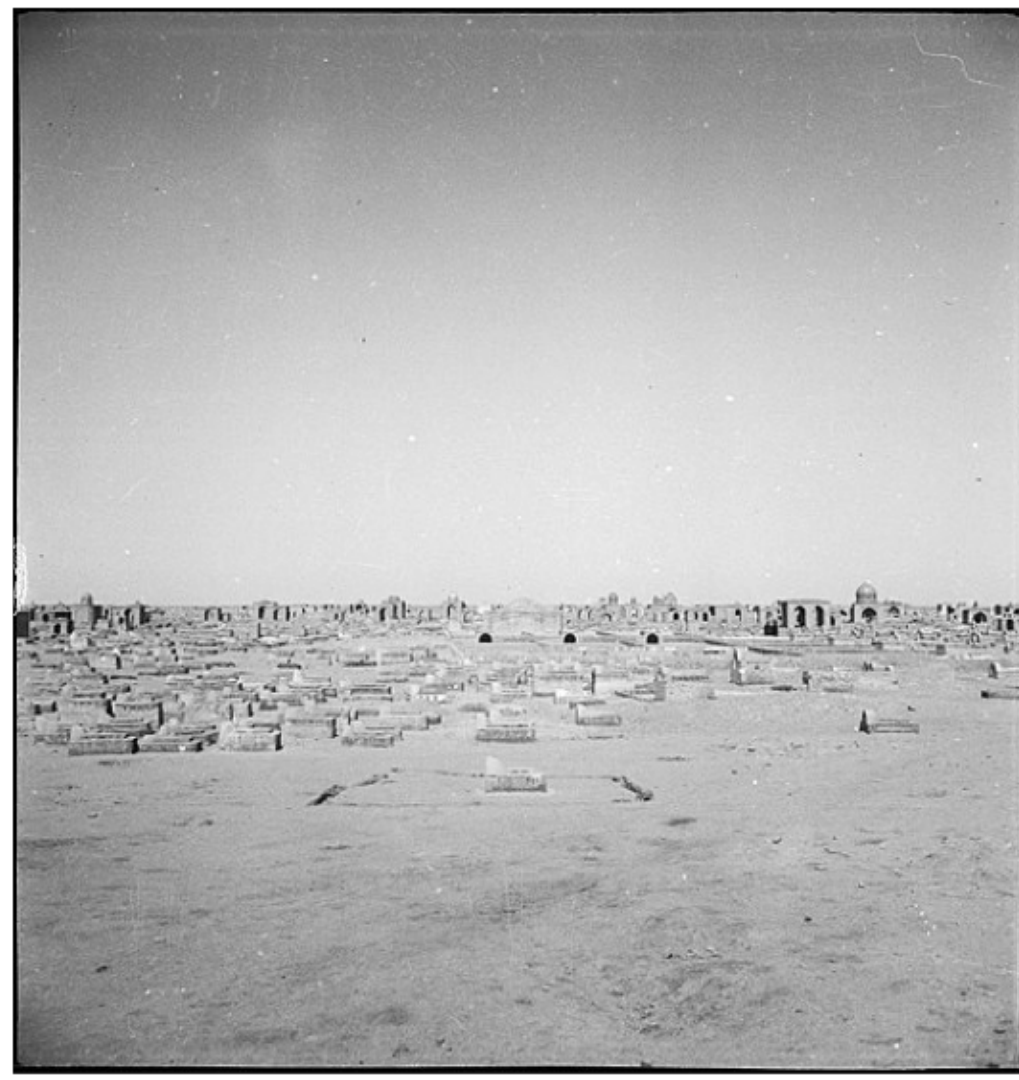

histórico de los yacimientos arqueológicos que visita, o cuando recuerda su patria suiza con cierta nostalgia: Al despertar tras la primera noche invernal y fría en Kayseri, la viajera se cree en una "heimatlichen Bauernstube" (27).

Algunos críticos han creído ver en estos momentos de confesión subjetiva la construcción, por parte de Schwarzenbach, de un "espacio híbrido” (Godinho 2014) o “tercer espacio" (Heinrichs 2010), como el que postulará 60 años después la teoría postcolonial. Otros estudios afirman, por el contrario, que Winter in Vorderasien perpetúa de forma sutil el modelo de pensamiento que Said (1995) definió como 'Orientalismo', por ejemplo, cuando Schwarzenbach asocia la despedida de Europa con la noche (Abendland) mientras la llegada a Asia tiene lugar por la mañana, haciendo referencia al Morgenland (Decock 2010: 58).

En mi análisis de la técnica literaria, en la que la perspectiva narradora se asemeja al objetivo de una cámara fotográfica, he encontrado indicios del 'Orientalismo' del que habla Decock (2010). Aunque estos indicios realmente son sutiles y prevalece la mirada despojada de prejuicios, creo que la interpretación basada en el postcolonialismo no da cuenta de cómo Schwarzenbach se aproximó a Oriente. Me parece más acertado hablar, como Schliecker (2008), de una experiencia intensa de lo culturalmente ajeno, sin llegar a domesticarlo (Schliecker 2008: 183). Schwarzenbach mantiene la dicotomía entre lo propio y lo 
ajeno, entre lo occidental y lo oriental. No lo sublima en un espacio intermedio ni se apropia de lo ajeno sometiéndolo a interpretaciones explicativas: ella está en Oriente, pero detrás de la cámara fotográfica.

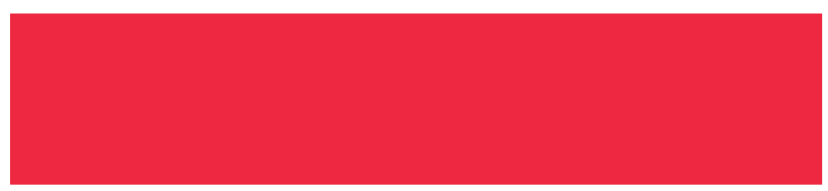

Bibliografía

Almarcegui, P. (2009): Una aproximación al Oriente de Annemarie Schwarzenbach, en Quaderns de La Mediterrània, 9, 239-244.

De Bruyker, M. (2011): Fotografisches Wahrnehmen. Visualität und Subjektivität in Annemarie Schwarzenbachs 'Das glückliche Tal', en Archiv für das Studium der neueren Sprachen und Literaturen, 248 (163), 22-40.

Decock, S. (2010): Papierfähnchen auf einer imaginären Landkarte. Mythische Topo- und Tempografien in den Asien- und Afrikaschriften Annemarie Schwarzenbachs, Aisthesis, Bielefeld.

Fähnders, R. (2008): Die literarsichen Anfänge von Annemarie Schwarzenbach, en Fähnders W. y Rohlf S. (eds.), Annemarie Schwarzenbach: Analysen und Erstdrucke. Mit einer Schwarzenbach-Biographie, Aisthesis, Bielefeld, 45-62.

Godinho, M. de L. N. (2014): A viagem como 'transcender de pátrias': 'nomadismo' e espaço híbrido em Annemarie Schwarzenbach, en Cadernos de Literatura Comparada, 30 (6), 219-235.
Heinrichs, P. (2010): 'Unser Leben gleicht einer Reise'. Türkei-Bilder in den Texten Annemarie Schwarzenbachs, en Globalisierte Germanistik: SpracheLiteratur-Kultur. XI. Türkischer Internationaler Germanistik Kongress (20.-22. Mai 2009 Izmir), 114-125.

Henke, S. (2010): Die Möglichkeit eines Zeichens. Annemarie Schwarzenbachs Beitrag zur Untersuchung von Kultur, en Carbone M. (ed.), Annemarie Schwarzenbach. Werk, Wirkung, Kontext. Akten der Tagung in Sils/ Engadin vom 16. bis 19. Oktober 2008. Mit einer Schwarzenbach-Biographie 2005-2009, Aisthesis, Bielefeld, 219234.

Said, E. W. (1995): Orientalism. Western conceptions of the Orient, Penguin Books, London.

Schliecker, K. (2008): 'Nach Osten! Anderen Himmeln entgegen!' Annemarie Schwarzenbachs Asienreisen im Spiegel ihrer Texte, en Fähnders W. y Rohlf S. (eds.), Annemarie Schwarzenbach: Analysen und Erstdrucke. Mit einer Schwarzenbach-Biographie, Aisthesis, Bielefeld, 169-185.
Schwarzenbach, A. (2008): Auf der Schwelle des Fremden. Das Leben der Annemarie Schwarzenbach, Collection Rolf Heyne, München.

Schwarzenbach, A. (1934): Winter in Vorderasien. Tagebuch einer Reise, Rascher \& Cie. A.-G., Zürich, Leipzig, Stuttgart, Wien.

Stempel, B. (2009): Asien sichten, VDG, Verlag und Datenbank für Geisteswissenschaften, Weimar.

Vilas-Boas, G.(2008): Das Wiedererkennen und das Erinnern in den Reisetexten Annemarie Schwarzenbachs, en Decock S. y Schaffers U. (eds.), inside out. Textorientierte Erkundungen des Werks von Annemarie Schwarzenbach, Aisthesis, Bielefeld, 153-172.

Fotografías

Procedentes de los archivos de www.helveticarchives.ch

1. CH-NB_-_Türkei,_Istanbul-_Menschen_-_Annemarie_Schwarzenbach_-_SLA-Schwarzenbach-A-5-02-015

2. CH-NB_-_Türkei,_Istanbul-_Menschen_-_Annemarie_Schwarzenbach_-_SLA-Schwarzenbach-A-5-02-003

3. CH-NB_-_Irak,_Nejaf_(Nedjef)-_Wüstenfriedhof_-_Annemarie_Schwarzenbach_-_SLA-Schwarzenbach-A-5-03-161

4. CH-NB_-_Syrien,_Aleppo-_Strassenszene_-_Annemarie_Schwarzenbach_-_SLA-Schwarzenbach-A-5-03-021 